\title{
Solar Water Pump
}

\author{
Ibrahim Alkhubaizi
}

\begin{abstract}
Solar powered water pumping systems have become the interest of many people in the recent years. Acknowledging that nature has provided a bounty of energy which can be converted into electrical energy has created innovative ways of discovering materials that can be used to make a system that supports turning heat into electricity. In this regard, the paper presented different concepts that relate to how the whole energy creation process is done and discusses useful ways of turning heat into useful energy. Furthermore, the recommendations dictate that while advancements in the technology are given attention, the issue of the investment cost and how it will thrive in the market is still a question. Nevertheless, many developing and developed countries continue to express interest in this area, and most are actively using and exploring how solar power can be used in other ways. Photovoltaic systems which are used to pump water for people, livestock and plants are an important move for technology and use of solar energy. Pumping water system using this PV technology has shown that is simple and that it does not require a lot of maintenance. In this regard, the idea gained the interest of farmers whose main concern is providing sufficient water not only for themselves but also for their plants and crops and livestock. The only major difference to this is that the system relies on solar energy as a power source for the pumps.

Keywords:

- Array - collection of photovoltaic modules electrically wired together in one structure to produce a specific amount of power

- Direct Current (DC) - Electric current (flow of electrons) in which the flow is in only one direction

- Displaced or Volumetric Pump - type of water pump that utilizes a piston, cylinder and stops valves to move packets of water

- Electric Power Plant - station containing prime movers, electric generators, and auxiliary equipment for converting mechanical, chemical or fission energy into electric energy

- Energy- "the capacity for doing work as measured by the capability of doing work (potential energy), or the conversion of this capability to motion (kinetic energy) ("Glossary - Florida Solar Energy Center (FSEC)).

- Energy Consumption - the use of energy as a source of heat or power or as an input in the manufacturing process

- Photovoltaic Energy -Direct-current electricity generated from sunlight through solid-state semiconductor devices that have no moving parts

- Photovoltaic (PV) System - "a complete set of interconnect components for converting sunlight into electricity by the photovoltaic process, including array, balance-of-system components, and the load." ("Glossary Florida Solar Energy Center (FSEC)")
\end{abstract}

\section{INTRODUCTION}

The most practical and best source of light and energy comes from the sun. It is the one source that doesn't run out and is made available to everyone without cost. So, it logically makes sense that people find a way to make the best out of what nature provides us so generously. One of the ways that this can be done is by converting the sun's light into useful electricity. Normally, when light touches an object, the energy is converted into heat. This is the same feeling when you go out and bask in the heat of the sun. For some materials, however, the energy is converted into an electrical current which can be used to generate power.

In the old days, solar technology would involve using silicon crystals to produce the elec- tric current when heat is received. When silicon receives heat from the sun, the electrons causes the crystals to move, transforming the light energy into electricity. The only problem is that big crystals are difficult to produce. Hence, the evolution of new materials meant smaller, cheaper materials and crystals like copper-indium-gallium-selenide which are shaped into usable, flexible films. The drawback to using this material, however, is that it does not compare to silicon's performance when it comes to converting energy into electricity.

In the recent years, increasing awareness of possible alternatives has been given attention, especially that solar energy is a great solution to acquiring electricity. However, while solar energy comes from a free source, the materials needed to produce a decent solar energy panel is expensive, 
that scientists and researchers need to develop materials that are cheap and can effectively convert sunlight into electricity.

Solar power can be especially useful in remote places where a general supply of electricity would be developed. Such is the case of farmers who need efficient ways of watering systems to help with the business of growing crops or managing livestock. Solar-powered water pumping solution and system is one of the answers to this. It would enable access to multiple distribution points, providing precious water to irrigations where needed and accessibility to clean animal pens and provide them with needed water.

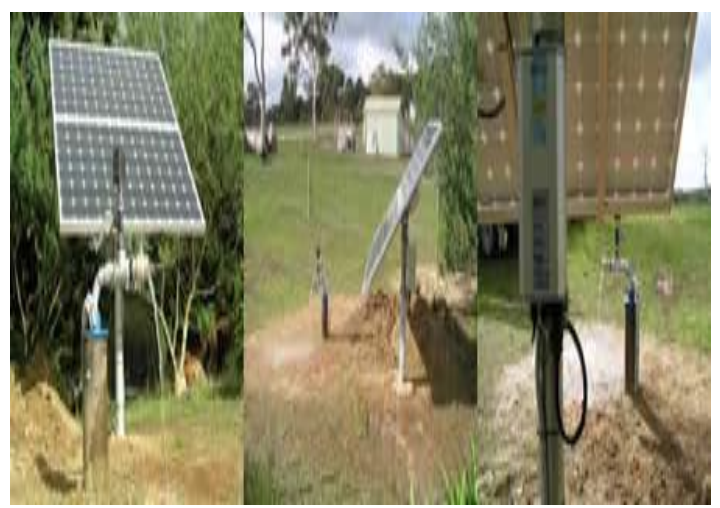

Figure 1: Solar Panels used in irrigation and livestock areas (Butler)

What the image above shows is an example of a solar panel system used in water pumps. Essentially, a solar powered pumping system would consist of a solar panel array which is used to power and the electric motor that causes a bore or surface pump to supply water is strategic farming and livestock areas. The interest hence of this paper is placed on a thorough discussion of how solar energy can be used to extract water from well pumps.

\section{Goals of the Research}

The study is interested in emphasizing the usefulness, potentials, and benefits. More particularly the study aimed at identifying how solar energy is used in well pumps so that it provides the needed water to strategic locations. One of the benefits of a solar pump is especially highlighted in farming and livestock use. But then, more importantly, solar pump systems provide a costeffective and more efficient means of providing priceless water to people.

\section{DISCUSSION}

The sun is like a natural nuclear reactor which releases tiny elements of energy called photons, "that travel the 93 million miles from the Sun to Earth in about eight-and-a-half minutes. Every hour, enough photons impact our planet to theoretically satisfy global energy needs for an entire year"(Butler). Needless to say, solar energy has been available since the solar system was formed billions of years ago. It was not observed until the $19^{\text {th }}$ century that Alexandre Edmond Becquerel discovered a breakthrough in solar energy's potential. Considered as the father of solar panels, he was able to prove that electric current could flow through an electrode exposed to sunlight. Interestingly, his discovery "showed that shining light on an electrode within a conductive solution generates an electrical current. This is known and now called as the photovoltaic effect, the same principle used in modern solar panels."("Who Invented Solar Panels?"). However, it took another century since the discovery, when Russel Ohl studied the information on photovoltaic effect and the invention of the transistor, to invent the solar cell. The solar cell becomes an efficient device to harness electricity from solar energy, particularly when integrated into a solar panel. Appropriately called photovoltaic (PV) solar panels, solar cells captures sunlight and converts it to direct current (DC) electricity.

\section{Solar Cells}

Silicon, a very good semiconductor, is the main component in a solar cell. Just like a battery, the solar cell is constructed with a positive and negative layer to form an electric field. The photons from the sun will hit the solar cell and excite the electrons from their atoms. The conditions are dictated by conductors which are attached to the positive and negative sides of a cell which forms an electrical circuit. "When electrons flow through such a circuit, they generate electricity" ("How Does Solar Energy Work?"). The more energy is required, the more solar cells are needed. If multiple solar cell panels are wired, it forms a solar array to generate more electricity.

Four types of solar panels are commonly available: single silicon, multi-silicon, BIPV (building integrated photovoltaics) and solar thermal panels. The most efficient type is the singlesilicon panel while the less efficient but less expensive to produce is the multi-silicon panel. The BPIV is designed to blend with the edifice of the structure or building, which make it very expensive. Solar thermal panels are not actual solar cell panels. They do not conduct electricity but absorbs the heat of the sun to warm the water. Larger solar thermal systems could heat up an entire building. ("How Many Types Of Solar Panels Exist?"). As mentioned, solar cells produce direct current (DC) electric output. What this means is that PV systems could directly supply electricity to DCspecified items like bulbs and batteries. If the solar cells are to be used to power alternating current 
(AC) devices like a generator or a motor or simply an AC lighting system, an inverter is needed to convert DC to AC. One of the first basic applications of the solar cells is to store power on batteries and supply household lights. The below image shows a fundamental PV system.

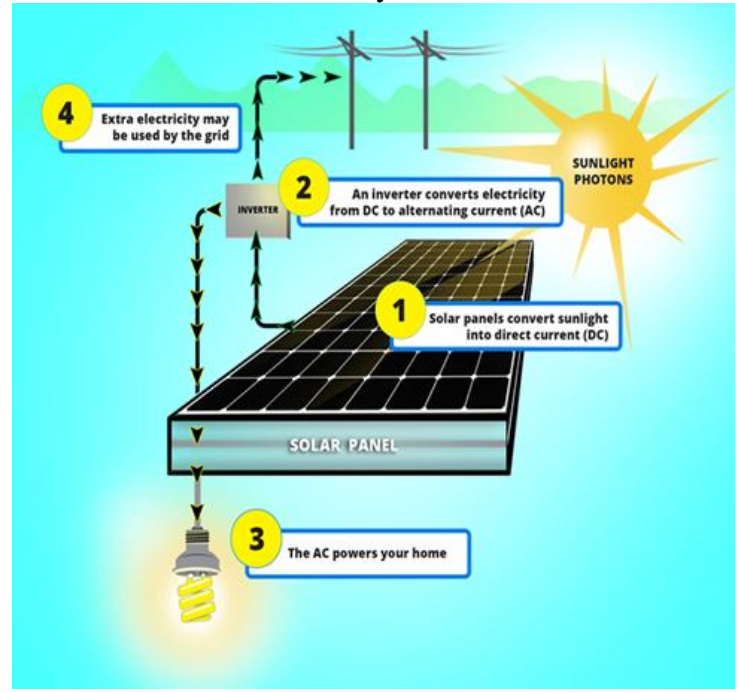

Figure 2: ("How Does Solar Energy Work?").

\section{Solar Powered Water Pumps}

This article is focused on one of the major application of solar power - operating or powering pumps or motors to extract water from the ground. Feasibility for any PV system should include a study of the Global Horizontal Irradiance (GHI). "GHI is the total amount of shortwave radiation received from above by a surface horizontal to the ground and is the most important parameter for evaluation of solar energy potential of a particular region..." ("The Future Of Solar Water Pumping"). From the map below, the efficiency and effectiveness of a PV system particularly depend on the amount of solar radiation being received on a site. Practically it will not be feasible to put a PV water pump system in cold places or where there are plenty of volcanic activities or cloud cover.
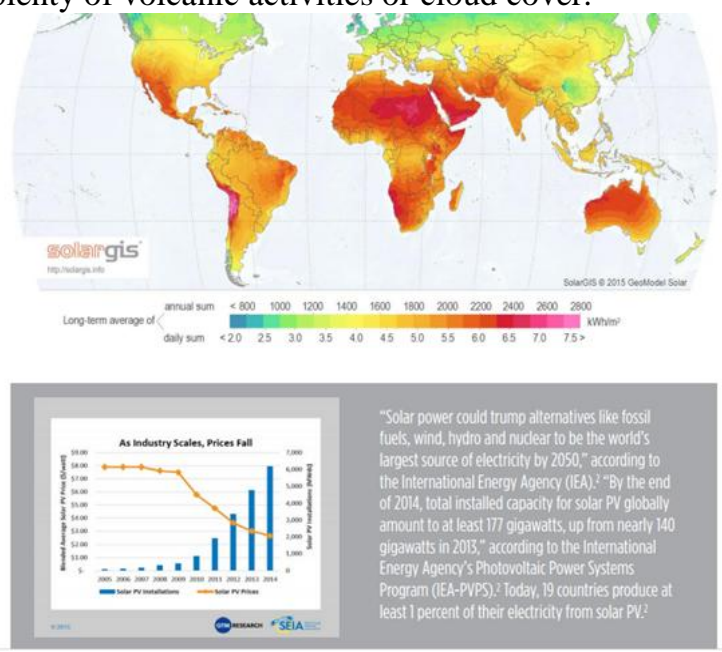

Figure 3: Map and statistics of the effects and effectiveness of solar power

("The Future Of Solar Water Pumping")

The figure below shows the calculation of GHI and Direct Normal Irradiance (DNI). This is defined as the amount of solar radiation received per unit area by a "surface that is always held perpendicular (or normal) to the rays that come in a straight line from the direction of the sun at its current position in the sky"(First Green Consulting). The amount of irradiance that is annually received by a surface can be maximized so that it maintains a normal status when exposed to incoming radiation. On the other hand, "Diffuse Horizontal Irradiance (DHI) is the amount of radiation received per unit area by a surface (not subject to any shade or shadow)" (First Green Consulting). What this means is that radiation does not directly come from the sun but has been dispersed by molecules and particles in the atmosphere (First Green Consulting).

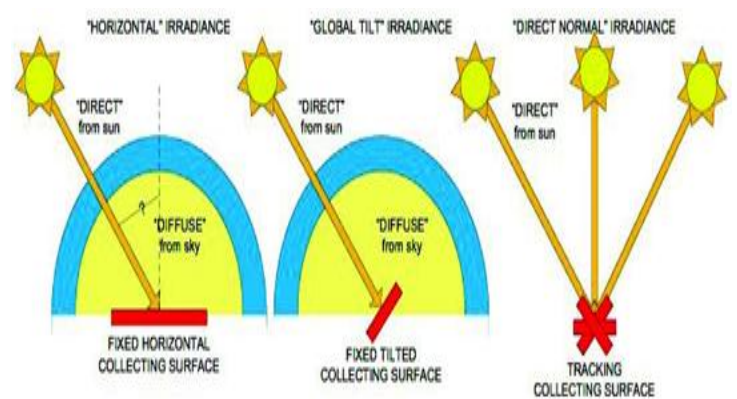

Figure 3: Illustration of the DHI Process (First Green Consulting)

\section{Solar Water Pump}

A solar water pump uses a mini powerhouse which is found at its center. This consists of important elements such as a calibrated and matching a solar array of modules, specially designed to match and withstand the equivalent power of pump for that particular application and use. Once this is established and is in place, the solar water pumping system would be able to process different types of electrical water pumps, as well as providing the needed water demand in various areas, from irrigation to household uses. Other systems such as irrigation pumps may be submersible, surface or deep well and can also be modified so that it caters to drip irrigation systems.

Furthermore, typical solar water pumping system is known by the "total of solar array size that is required to run the attached pump" ("Solar Water Pumps"). What can be seen is that typically, a $1000 \mathrm{Wp}$ solar water pump can gather an amount of about 40,000 liters of water every day taken from a source that is up to 10 meters deep. This would be enough to supply and irrigate about 2 
acres of land with regular crops. Meanwhile, a $1000 \mathrm{Wp}$ solar water pump helps save up to Rs 45,000 when compared to an equivalent use of a diesel-operated pump over a year ("Solar Water Pumps").

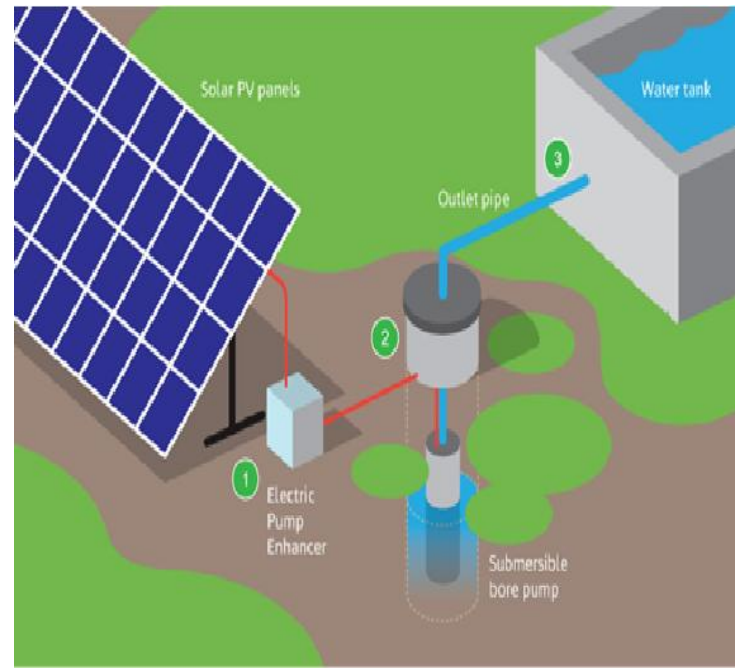

Figure 4: Solar Water Pump Mechanism ("Solar Water Pumps")

The process of how the solar panel works involve some steps. As each solar array has some solar modules that are connected in series or parallel connection. Each solar PV panel creates the electric current by changing the solar radiation it receives into electrical energy. This electrical energy is enhanced, manipulated and goes through an inbuilt controller in DC pumps and allows a connected pump to work so that it draws water taken from different sources such as ponds, rivers, wells and other sources. The water then that goes through a feed of pipelines and supplies irrigation systems and livestock areas with the needed water.

\section{RECOMMENDATIONS}

The study showed how solar energy can be converted and turned into useful energy to power water systems. However, there are considerations to the use of well pumps to extracting water. While there is an increasing awareness of its usefulness and that alternatives to materials used in creating solar panels that would provide the energy to pump water systems, the materials used are still expensive materials and would need a considerable amount of investment and that there would be implications to doing so as well. However, this is outweighed by more important effects. For instance, a swimming pool requires massive amounts of energy to keep it clean. A solar pump would save on energy bill and would also ensure that the pool is environmentally clean. It is worth noting, however, that while a proposal to extracting water through solar energy is environment-friendly and would lead to many benefits, it is important that more studies be taken to further develop more economical ways of extracting water by solar energy.

\section{CONCLUSION}

Solar pumps are evidently seen as efficient, environmentally friendly way to produce and supply water demands of many domestic and commercial purposes. Nowadays, the use of the solar system is highlighted in many agricultural and residential irrigation and cattle or livestock watering solutions. One clear advantage of solar pumps is that they can be easily installed and do not require heavy maintenance. Additionally, these pumps can survive up to 20 years, so that the benefit made on it outweighs the initial set up costs. However, aside from the economic and environmental benefits of solar powered water pumps, there are many other advantages that make them more appealing than battery or any other conventionally powered pumps. For instance, as solar pumps do not rely on electricity or produce dangerous toxins. Thus, they are safe. Secondly, solar power pumps can be used to supply heat to homes and public buildings. Another benefit is that they operate quietly. Finally, they are self-priming and are easy to install.

Today, the viability and practicality solar energy as a future energy source is quickly becoming known all over the world. Installations of small and Solar PV Power Systems are increasing significantly. Solar PV systems show that people are becoming more aware of the potentials and possibilities of solar power energy. It goes on to say that the idea of solar power has become an interest for many including businesses that many investments are made in different types of energy conversion systems to suit the people's needs. Such is seen in Solar PV \& Solar Thermal Power Plants, Solar Powered Electronic items, Solar Water Heater systems. Even satellites are now powered by solar panels. The discussion on how solar energy systems can be utilized to pump water and serve people effectively without depending on the grid power supply leads to clean energy that a continuous development of the idea of solar energy is being raised and is observed in many parts of the world.

\section{REFERENCES}

[1]. Butler, Roy. "Solar-Powered Water Pumping | Home Power Magazine."Homepower.Com, 2014, https://www.homepower.com/articles/sola r-electricity/design-installation/solarpowered-water-pumping? $\mathrm{v}=$ print. 
[2]. First Green Consulting. "Differentiate Between The DNI, DHI And GHI?". Firstgreenconsulting.Wordpress.Com, 2012, https://firstgreenconsulting.wordpress.com /2012/04/26/differentiate-between-the-dnidhi-and-ghi/.

[3]. "How Does Solar Energy Work?". Sun Power, 2015 , https://us.sunpower.com/blog/2015/06/15/ how-does-solar-energy-work/.

[4]. "How Many Types Of Solar Panels Exist?".

Reference, https://www.reference.com/science/manytypes-solar-panels-exist-

b1a4d6cacd7bc299?qo=contentSimilarQu estions\#.

[5]. "SolarWaterPumps."Tatapowersolar.Com, http://www.tatapowersolar.com/SolarWater-Pump.

[6]. "THE FUTURE OF SOLAR WATER PUMPING." http://solar.franklinelec-

tric.com/media/11621/Solar_Backgrounde r_Full-FINAL.pdf.

[7]. "Who Invented Solar Panels?". Reference, https://www.reference.com/history/invente d-solar-panels-37af75d5d352dcd\#. 